\title{
INSTRUCTIONAL VIDEOS, CONCEPTUAL UNDERSTANDING AND SELF-EFFICACY IN THE TIME OF COVID-19
}

\author{
Smitha Jose ${ }^{a}$, Raji Kochandrab ${ }^{b}$ Scott Daniel ${ }^{c}$ \\ Presenting Author: Smitha Jose (smithajose@swin.edu.au) \\ ${ }^{a}$ Faculty of Science, Engineering and Technology, Swinburne University of Technology, Hawthorn VIC 3122, Australia \\ ${ }^{\mathrm{b} T e a c h e r}$, Science Engineering \& Technology, Swinburne Academy, Swinburne University, Hawthorn, Australia \\ 'Faculty of Engineering and Information Technology, University of Technology Sydney, Ultimo NSW 2007, Australia
}

KEYWORDS: conceptual understanding, self-efficacy, online instruction, COVID-19, videos

Advances in technology are bringing new affordances in teaching. Many students engage with online videos that enable them to watch, and re-watch, support materials. In our large-enrolment introductory first-year physics unit, many students find the content very challenging. To support their learning, we have developed short videos of 4-5 minutes explaining concepts and problem-solving.

Our study was originally designed to evaluate and compare the effect on conceptual understanding and self-efficacy of students engaging with two different types of videos: Screencasts (e.g. Khan Academy style) and Lightboard videos, where the teacher presents direct to the camera on a writable transparent board (the image is then inverted to be the right way around).

Then COVID-19 struck, and all our learning was moved online. This has given us an opportunity to ask some deeper questions of the data we have been collecting. More than just comparing the effectiveness of Screencasts versus Lightboards, we are now able to investigate the influence of the shift to online teaching from COVID-19 and therefore how online engagement relates to the selfefficacy and conceptual understanding of students. We measured self-efficacy using the Physics SelfEfficacy Questionnaire (Lindstrøm \& Sharma, 2011) and measured conceptual understanding using both the 'Conceptual Connections' statements from the CLASS survey (Adams et al., 2006) and exam performance on conceptual questions.

We found that students, on average, watched considerably more Lightboard videos than Screencasts. However, we observed comparable learning gains with both video modes. Surprisingly, we observed improved scores on the self-efficacy instrument for the students that responded to both the pre- and post-survey, at odds with what Lindstrøm \& Sharma (2011) had previously observed with a comparable cohort, but this may be a self-selection bias or an artefact of the small number of students that responded on both occasions $(n=11)$. We also compared performance on the CLASS 'Conceptual Connections' statements with exam performance on conceptual questions and unexpectedly found a weak negative correlation $(r=-0.20, n=21)$, which challenges the validity of that CLASS category. We are collecting further data in this current semester with the goal of firming up some of our conclusions with a larger sample size.

\section{REFERENCES}

Adams, W.K., Perkins, K.K., Podolefsky, N.S., Dubson, M., Finkelstein, N.D., \& Wieman, C.E. (2006). New instrument for measuring student beliefs about physics and learning physics: The Colorado Learning Attitudes about Science Survey. Physical Review Special Topics- Physical Education Research 2(1), 010101-1--010101-14.

Lindstrøma, C. \& Sharma, M. (2011). Self-Efficacy of First Year University Physics Students: Do Gender and Prior Formal Instruction in Physics Matter? International Journal of Innovation in Science and Mathematics Education, 19(2), 1-19. 